and making greater use of the energy derived from biomass, either on farms or through industrial processing (S. Long, Univ. Illinois, USA). Some delegates argued that a reduction in meat consumption would be an effective way to reduce UK emissions, although others felt that efficient animal production systems in the UK could help to meet the rising demand for meat elsewhere in the world at the lowest cost in terms of emissions.

Various approaches to ranking and costing the full range of mitigation activities were considered (D. Moran, Scottish Agricultural College, UK; P. Lowe, Univ. Newcastle, UK) and the challenge of accurately measuring emissions, and discerning the benefit of actions at the individual farm level, were discussed (K. Goulding, Rothamstead Research, UK). Throughout, concerns were expressed about balancing the positive effects on greenhouse gas emissions against negative effects elsewhere in the system, such as increased nitrate leaching or reduced biodiversity (I. Crute, Agriculture and Horticulture Development Board, UK).
Concerns were also raised that present accounting methods do not credit farmers for emissions reductions associated with the sequestration of carbon in soils, or the production of carbon-neutral energy and feedstocks from land. Some grazing systems were shown to be carbon neutral when these factors were included (J-F. Sousanna, INRA, France). By jointly considering both mitigation and abatement, carbon sequestration could present a significant opportunity for the sector.

The desirability, within the global food market, of considering emissions at the country level was discussed. A number of delegates (the author included!) argued that exporting food production should not be seen as a mitigation option, given that net greenhouse emissions per unit product would probably increase, and that the UK would lose the ecosystem services associated with that production. Considering the atmosphere as a common resource is vital for ensuring appropriate mitigation efforts, and avoiding unwanted consequences (P. Lowe, Univ. Newcastle, UK).
New approaches - such as the application of compounds that impede nitrous oxide production in soils - could soon be available to help with mitigation efforts. Others, especially those reliant on an improvement in the efficiency of carbon capture or nutrient uptake by crops, are unlikely to emerge this decade (S. Long, Univ. Illinois, USA).

The London meeting on reducing greenhouse gas emissions from agriculture highlighted the importance of cutting inefficiencies in present farming practices. There was an appreciation that research related to carbon and nitrogen cycling in soils is important. However, the most important next step will be the less glamorous strategies of reducing waste across the food chain and improving farm performance, in what will have to be a process of evolution rather than revolution.

Chris Pollock is at Aberystwyth University, Penglais, Aberystwyth SY23 3DA, UK.

e-mail: cip@aber.ac.uk

\title{
PALAEONTOLOGY
}

\section{Land-locked life}

The history of life in the oceans on early Earth is well preserved in thick sequences of marine sediments exposed in Australia and South Africa. These rocks reveal the progression of life over the course of billions of years, from simple bacteria to more complex eukaryotic cells. However, the history of life on land is more difficult to ascertain. Microfossils are rare, and the presence of microbes in terrestrial environments is most often inferred by variations in the isotopes of elements such as carbon and iron, and from the presence of structures reminiscent of microbial mats. Indeed, the earliest putative marine bacteria are 3.5 billion years old, whereas the most commonly cited terrestrial microfossils date back only 1.2 billion years.

These terrestrial fossils - known as the Torridonian microfossils - come from ancient lake and river sediments in northwest Scotland. Paul Strother of Boston College, Massachusetts, and colleagues returned to the Torridonian site and found a wealth of wellpreserved microfossils that allowed them to describe the three-dimensional structure of the individual fossils (Nature doi:10.1038/nature09943; 2011). The

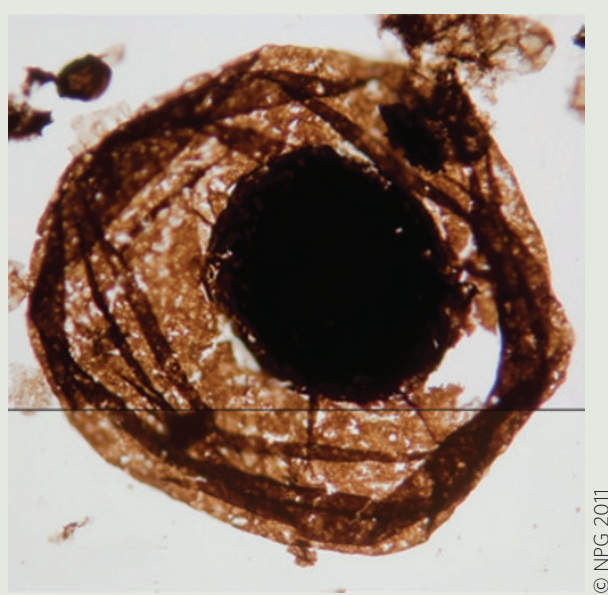

thicknesses and compositions. Some walls had ornamentation, as well. Intriguingly, the fossils also showed a number of features - such as sutures or highly ordered arrangements of numerous cells consistent with eukaryotic organisms.

The cells of eukaryotes comprise complex structures enclosed by membranes. These structures are lacking in the bacteria and archaea that made up the earliest life on Earth. Eukaryotes appeared in the marine record at least 1.5 billion years ago (probably much earlier), but reports of their terrestrial counterparts before 540 million years ago are sparse.

The finding of a wide range of

reconstructions revealed an array of body shapes and organic structures, and even some cell clusters that verged on tissuegrade organization.

The fossils, which range from tens of micrometres to almost a millimetre in diameter, exhibit a wide variety of morphologies. A number of fossils were broadly spherical, whereas some had spines and others arm-like projections. Many had complex cell walls, with different eukaryotic fossils in the 1.2-billion-year-old Torridonian rocks suggests that freshwater habitats were colonized by eukaryotes earlier than previously thought. However, although the organisms were able to survive during periods of desiccation, it is unclear whether they were able to thrive for long periods outside of aquatic conditions. The search for early life on dry land is therefore far from over.
ALICIA NEWTON 